\title{
Dynamic modelling of the thermal space of the metallurgical walking beams furnaces
}

\author{
D. Constantinescu \\ Material's Science and Engineering, \\ University POLITEHNICA of Bucharest, Romania
}

\begin{abstract}
The aim of the paper is to establish the basics of a model in order to help the evaluation of the parameters of the heat transfer and energy consumption in the case of the walking beam furnaces for rolling mills. The heating process of alloyed and high-alloyed steel billets in view of processing by rolling is analyzed. The temperature gradients, producing internal thermal stresses in the heated material, are a problem that influences the design of the aggregate. If the values of the thermal stresses exceed the tensile strength they can lead to the destruction of the finished product. The thermal stresses are mostly due to the poor correlation of heating process of the billets in typical furnaces for rolling mills with mechanical and thermal characteristics of the heated material and with the dynamic of the gases. Using physical and mathematical modelling, there are established correlations between the thermal process, the dynamic of the gases and the particularities of the furnace in order to obtain the conditions for modelling a variable geometry of the aggregate. The particularities of the steels and of the furnace are analyzed in order to reach an optimum of the geometrical model for the thermal space. Physical and mathematical models are used to establish a new variable geometry. Saving energy and metal, due to the chemical, thermal and dynamic processes, means having a cleaner environment. A new disposal system of the burners inside the furnace and a new variable geometry of the thermal space can lead to energy and metal savings. The conclusions of the study are applied for a new design of the furnace, including dynamic aspects of the geometry of thermal space.
\end{abstract}

Keywords: furnace, metallurgy, modelling, dynamic of the gases, thermal space. 


\section{Temperature and thermal stresses in steel billets}

A study of the mechanism of thermal stresses and the establishing of the critical thermal values was imposed in order to include its influence on the mathematical remodelling of the thermal space [1-3].

\subsection{The case of the cylindrical billets}

Using the Bessel functions, and having the notes:

$\theta_{\mathrm{c}}$ : furnace temperature

$\theta_{\text {mi }}$ : temperature in the centre of the billet

$\theta_{\mathrm{m} 0}$ : initial temperature of the billet

$\theta_{\mathrm{ms}}$ : temperature at the surface of the billet (its value is determined subject to upper or lower surface).

$\theta_{\mathrm{mf}}$ : final temperature of the billet

It was deduced for a cylindrical billet:

- temperature for the surface:

$$
\theta_{m s}-\theta_{c}=\left(\theta_{m 0}-\theta_{c}\right)\left[v_{1} \cdot \varphi_{1} \cdot J_{0}\left(n_{1} R\right)\right]
$$

- $\quad$ average final temperature

$$
\theta_{m f}-\theta_{c}=\left(\theta_{m 0}-\theta_{c}\right)\left[v_{1} \cdot \varphi_{1} \cdot \frac{2 J_{1}\left(n_{1} R\right)}{n_{1} R}\right]
$$

Temperature's equation in the section of the cylinder may be expressed by:

$$
\begin{gathered}
\theta_{m}=\theta_{c}-\left(\theta_{c}-\theta_{m i}\right) \cdot J_{0}\left(\frac{r}{R} \sqrt{2 t-\frac{R}{\lambda}}\right) \\
t=\frac{\theta_{m s}-\theta_{c}}{\theta_{m f}-\theta_{c}}=\frac{J_{0}\left(n_{1} R\right)}{\frac{2 J_{1}\left(n_{1} R\right)}{n_{1} R}}
\end{gathered}
$$

Only the first component of the series was used, so, it is necessary to put the condition: $a \cdot \tau / R_{R^{2}} \geq 0,3$, (a: thermal diffusivity, $\tau$ : time).

Examples of the application of the model for the temperatures are presented in figures $1-4$.

For information about the values of the thermal stresses in the round section billet it is used the Bessel function $\mathrm{J}_{0}\left(\mathrm{n}_{1} \mathrm{R}\right)[4,5]$. If " $R$ " is the cylinder radius and " $r$ " the current radius, for $r=R$ the stresses $\sigma_{\text {tgs }}$ and $\sigma_{\text {azs }}$ at the surface of the billet are:

$$
\sigma_{\text {tgs }}=\sigma_{\text {axs }}=\frac{\beta \cdot E}{1-v} \cdot \Delta \theta\left[v_{1} \cdot \varphi_{1} \cdot J_{0}\left(n_{1} R\right)\right]
$$




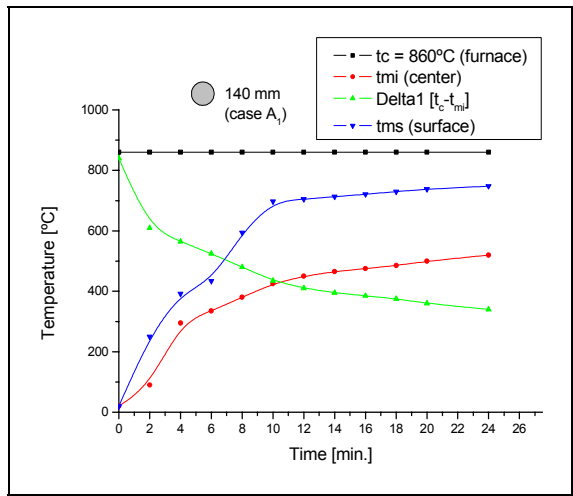

Figure 1: Temperatures in the cylindrical billet (140mm).

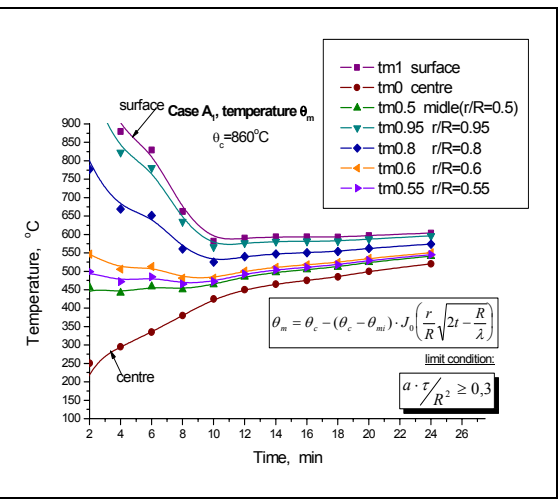

Figure 2: Analysis of the temperature in the cylindrical billet.

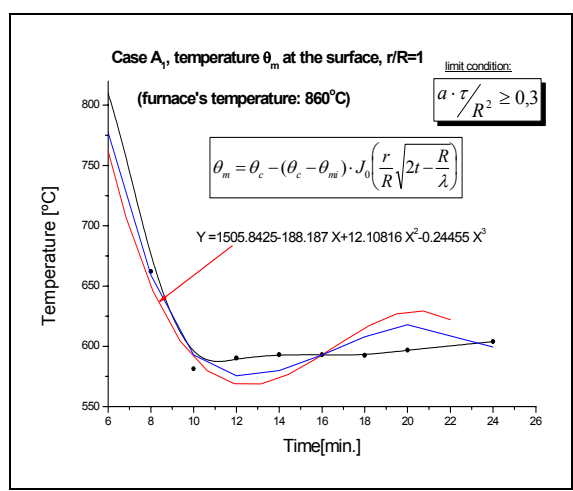

Figure 3: Detail for the temperature at the surface $\quad(\mathrm{r} / \mathrm{R}=1)$ $\left(\mathrm{t}_{\mathrm{m} 1}\right.$ in figure 2$)$.

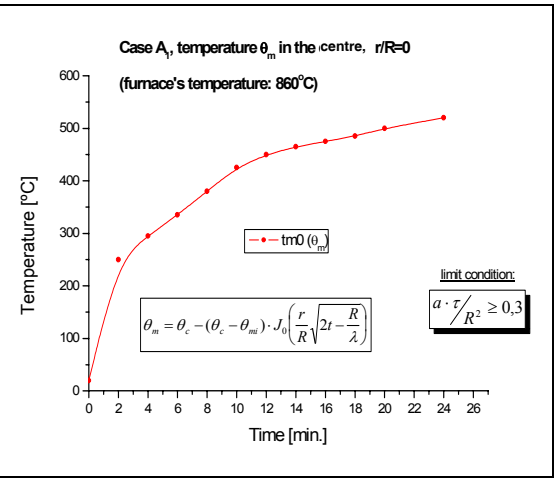

Figure 4: Detail for the temperature in the centre $(r / R=0)\left(t_{m 0}\right.$ in figure 2).

For $\mathrm{r}=0$, in the axis $\sigma_{\operatorname{tgax}}$ and $\sigma_{\text {rax }}$ are:

$$
\sigma_{r \text { ax }}=\sigma_{\text {tg ax }}=\frac{\beta \cdot E}{1-v} \cdot \Delta \theta\left[v_{1} \cdot \varphi_{1}\right]
$$

For whole section of the cylinder, if the heating is symmetrical $\left(\Delta \theta_{1}=\Delta \theta_{2}\right)$ :

$$
\sigma_{r}=\sigma_{t}=\frac{\beta \cdot E}{1-v} \cdot \Delta \theta\left[v_{1} \cdot \varphi_{1} \frac{2 J_{1}\left(n_{1} R\right)}{n_{1} R}\right]
$$

$\beta$ : coefficient of dilatation

E: Young module

$v$ : Poisson coefficient 
$v_{1}, \varphi_{1}$ : series of Bessel function

$\Delta \theta$ : temperature gradient

\subsection{The case of the rectangular section billets}

In the case of billets with rectangular section with the dimension " $X$ ", the admitted thermal stresses reported to the variable (x) axis, equations (8) and (9) [6] are proposed:

- $\quad$ axial and tangential stress in the axis of the billet, $\sigma_{\mathrm{xax}}$ and $\sigma_{\mathrm{yax}}$ :

$$
\sigma_{x \text { ax }}=\sigma_{y \text { ax }}=\frac{\beta \cdot E}{1-v} \cdot \Delta \theta \cdot\left[v_{1} \cdot \varphi_{1}\right]=\frac{\beta \cdot E}{1-v} \cdot \Delta \theta \cdot \frac{\theta_{c}-\theta_{m i}}{\theta_{c}-\theta_{m 0}}
$$

- $\quad$ axial and tangential stress at the surface of the billet, $\sigma_{\mathrm{xs}}$ and $\sigma_{\mathrm{ys}}$ :

$$
\sigma_{x \mathrm{~s}}=\sigma_{y s}=\frac{\beta \cdot E}{1-v} \Delta \theta\left[v_{1} \cdot \varphi_{1} \cdot \cos \left(n_{1} X\right)\right]=\frac{\beta \cdot E}{1-v} \Delta \theta \cdot \frac{\theta_{c}-\theta_{m s}}{\theta_{c}-\theta_{m 0}}
$$

The values of the thermal stresses in whole section of the rectangular billet are:

$$
\sigma_{m}=\frac{\beta \cdot E}{1-v} \Delta \theta\left[v_{1} \cdot \varphi_{1} \cdot \frac{\sin \left(n_{1} X\right)}{n_{1} X}\right]=\frac{\beta \cdot E}{1-v} \Delta \theta \cdot \frac{\theta_{c}-\theta_{m f}}{\theta_{c}-\theta_{m 0}}
$$

\subsection{Influence of the thermal regime on the furnaces' design}

In figure 5 is explained the relation between the heating conditions necessary for a specific category of steels and the geometry of the vault.

The model that connects the thermal stress and the thermal field of the aggregate is obtained by simulation on the computer.

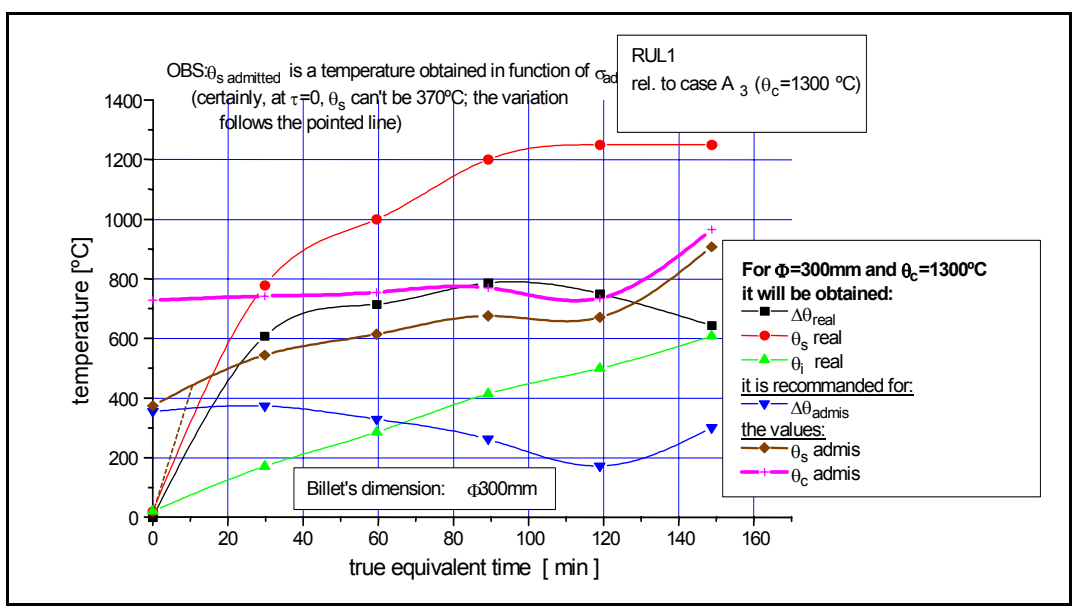

Figure 5: Maximum admitted temperature of the aggregate $\left(\theta_{\text {c-admis }}\right)$ in concordance with the maximum admitted temperature gradient $\Delta \theta_{\text {admits }}$ (billet radius $300 \mathrm{~mm}$; if the temperature of the aggregate is $1300^{\circ} \mathrm{C}$ the values are $\left.\theta_{\text {s real }}, \theta_{\mathrm{i} \text { real },} \Delta \theta_{\text {real }}\right)$. 


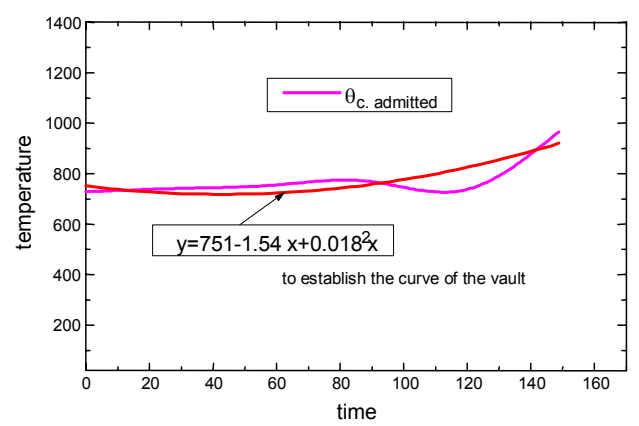

Figure 6: $\quad$ Basic profile of the vault (beginning temperature: $750^{\circ} \mathrm{C}$ ).

The results concerning the modelling of thermal fields in the furnace are used as a component included to the re-modelling of the thermal space of the aggregate.

Starting from the diagrams that show the thermal regime for the aggregate, it was proposed to use computer modelling, see the design of the vault of a furnace (figure 6) [7].

\section{The problem of energy and mass transfer}

In order to efficiently manage the mathematical model that describes the geometry of the thermal space of the aggregate, it is necessary to know the relations between the temperature of the steel, the temperature of the thermal isolation and the temperature of the flue gases.

The thermal output $\eta_{t}$, gives the energetic efficiency. It is strongly connected to the energy transfer problems. Equation (11) [7] was established

$$
\eta_{t}=1+\lambda_{a} \cdot v_{0 a} \cdot \frac{\theta_{a} \cdot c_{a}}{Q_{b}}+\frac{\theta_{b} \cdot c_{b b}}{H_{i}}-\frac{v_{o t} \cdot \theta_{g a} \cdot c_{p}}{Q_{b}}-\left(\lambda_{a}-1\right) \cdot v_{0 a} \cdot \frac{\theta_{g a} \cdot c_{a}}{Q_{b b}}
$$

where are used the notations:

$\mathrm{v}_{\mathrm{oa}}$ : theoretical volume of air combustion related to the thermal unit of the fuel $\left[\mathrm{m}^{3}{ }_{\mathrm{N}} / 10^{3} \mathrm{~kJ}\right]$

$\lambda_{\mathrm{a}}$ : air combustion excess coefficient

$\theta_{\mathrm{a}}$ : air combustion temperature, ${ }^{\circ} \mathrm{C}$

$\mathrm{c}_{\mathrm{a}}$ : thermal capacity of the air, $\mathrm{kJ} \cdot \mathrm{m}^{-3}{ }_{\mathrm{N}} \mathrm{K}^{-1}$

$\mathrm{c}_{\mathrm{p}}$ : thermal capacity of the flue gases,

$\mathrm{H}_{\mathrm{i}}$ : thermal energy of the fuel, $\mathrm{kJ}^{-3}{ }_{\mathrm{N}}$

Defining "the factor of the fuel" [7] as: $K_{c b}=1+\frac{\theta_{c b} \cdot c_{c b}}{H_{i}}$ :

$$
\eta_{t}=K_{c b}+\frac{1}{Q_{c b}}\left(\lambda_{a} \cdot v_{0 a} \cdot \theta_{a} \cdot c_{a}-v_{0 t} \cdot \theta_{g a} \cdot c_{p}-\left(\lambda_{a}-1\right) \cdot v_{0 a} \cdot \theta_{g a} \cdot c_{a}\right)
$$

The connection between the temperature of the gases, the temperature of the thermal isolation and the temperature of the billets is described by the equation: 


$$
\theta_{g} \cdot\left(\alpha_{g p} \cdot \varepsilon_{p}+\alpha_{c}\right)=\theta_{p} \cdot\left(\alpha_{g p} \cdot \varepsilon_{p}+\alpha_{c}+\chi \cdot \alpha_{p m} \cdot \varepsilon_{p m}-\chi \cdot \alpha_{g p m} \cdot \varepsilon_{p m}\right)-\theta_{m} \cdot\left(\sigma \alpha_{p m} \cdot \varepsilon_{p m}-\alpha_{g p m} \cdot \varepsilon_{p}\right)+q_{e x}
$$

$\alpha_{\mathrm{gpm}}$ : heat exchange coefficient from the gases to the metallic material, if it is considerate that the temperature of the gases is the same with the temperature of the thermal isolation, $\mathrm{kJ} \cdot \mathrm{m}^{-2} \cdot \mathrm{h}^{-1} \cdot \mathrm{K}^{-1}$

$\alpha_{\mathrm{pm}}$ : heat exchange coefficient by radiation between the thermal isolation and the metal, $\mathrm{kJ} \cdot \mathrm{m}^{-2} \mathrm{~h}^{-1} \cdot \mathrm{K}^{-1}$

$\alpha_{\mathrm{gp}}$ : radiation heat exchange coefficient between the gases and the thermal isolation, $\mathrm{kJ}^{-2} \cdot \mathrm{h}^{-1} \cdot \mathrm{K}^{-1}$

$\alpha_{c}$ : convection heat exchange coefficient between the gases and the thermal isolation, $\mathrm{kJ}^{-2} \cdot \mathrm{h}^{-1} \cdot \mathrm{K}^{-1}$

$\theta_{\mathrm{g}}$ : temperature of the flue gases, ${ }^{\circ} \mathrm{C}$

$\theta_{\mathrm{p}}$ : temperature of the thermal isolation, inside the furnace, ${ }^{\circ} \mathrm{C}$

$\varepsilon$ : thermal emissivity coefficients

$$
\chi=s / S
$$

where

$\mathrm{s}$ : heated surface of the billets, $\mathrm{m}^{2}$

$\mathrm{S}$ : surface of the thermal isolation, $\mathrm{m}^{2}$

$\mathrm{q}_{\mathrm{ex}}$ : the conduction thermal flow

Referring to equation (13) the complex heat exchange in the furnace is characterized by:

- the heat exchange coefficient between the thermal isolation and the billets

$$
\alpha_{1}=\frac{\alpha_{g m} \cdot \varepsilon_{m}+\alpha_{c}}{\alpha_{g p} \cdot \varepsilon_{p}+\alpha_{c}} \cdot\left(\alpha_{g p} \cdot \varepsilon_{p}+\alpha_{c}+\sigma \cdot \alpha_{p m} \cdot \varepsilon_{p m}-\sigma \cdot \alpha_{g m} \cdot \varepsilon_{p}+\frac{q_{e x}}{\theta_{p}-\theta_{m}}\right)
$$

- the heat exchange coefficient between the flue gases and the billets

$$
\alpha_{2}=\frac{\alpha_{p m} \cdot \varepsilon_{p m}-\alpha_{g m} \cdot \varepsilon_{p}}{\alpha_{g p} \cdot \varepsilon_{p}+\alpha_{c}+\sigma \cdot\left(\alpha_{p m} \cdot \varepsilon_{p m}-\alpha_{g m} \cdot \varepsilon_{p}\right)} \cdot\left(\alpha_{g p} \cdot \varepsilon_{p}+\alpha_{c} \frac{q_{e x}}{\theta_{g}-\theta_{m}}\right)+\alpha_{g m} \cdot \varepsilon_{m}+\alpha_{c}
$$

For particular cases, more friendly forms of the equations may be established. For example, if the fuel is the natural gas, the temperature of the flue gases is:

$$
\theta_{g}=\alpha_{p} \cdot \theta_{p}+\alpha_{m} \cdot \theta_{m}+\frac{q_{e x}}{0,8 \cdot \alpha_{g p}+\alpha_{c}}
$$

where

$$
\begin{gathered}
\alpha_{p}=\frac{0,8 \cdot\left[\alpha_{g p}+\alpha_{c}+\sigma\left(\alpha_{p m}-\alpha_{g p m}\right)\right]}{0,8 \cdot \alpha_{g p}+\alpha_{c}} \\
\alpha_{m}=\sigma \frac{0,8\left(\alpha_{p m}-\alpha_{g p m}\right)}{0,8 \cdot \alpha_{g p}+\alpha_{c}}
\end{gathered}
$$

Equation (16) can also have different forms according to the model of the furnace. 


\section{Dynamic of the gases in the aggregate}

In order to obtain the most adequate thermal regime, it is necessary to assure an advanced circulation and recirculation of the gases and to have permanently under control the parameters of their dynamic.

Certainly, a study using a physical model is also necessary. In order to accomplish this study and to use the obtained results for the real case it is needed to establish some non-dimensional criteria. The theory of similitude was applied.

In figure 7 the physical model for the walking beams furnace and an experimental result concerning the dynamic of the gases is presented.

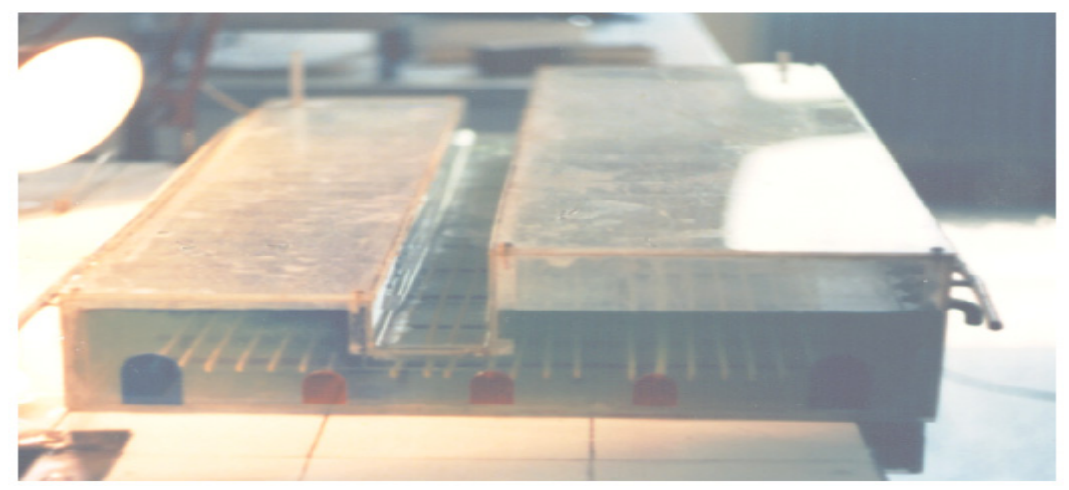

Figure 7: The experimental physical model for the recirculation of the flue gases in the case of the walking beam furnace.

The recirculation of the gases has some particular characteristics explained by the geometrical limits of the thermal space. In figure 8 (senses 2 and 2), the circulation is at the superior surface of the billets and produces a secondary degree recirculation.

The debit recycled in the "primary heating zone" and "secondary heating zone" can be calculating using equation (19).

$$
m_{r}=m_{0} \cdot\left(0,2 \frac{X_{f}}{r_{0}}-1\right)
$$

$\mathrm{m}_{\mathrm{r}}$ : mass of recycled gases

$\mathrm{m}_{0}$ : masse of the gases at the exit from the burner

$\mathrm{r}_{0}$ : burner's radius

As results of experiments and mathematical modelling it was remarked the influence of the temperature on the general dynamic of the gases in the continuous linear furnace (walking type furnace, figure 8).

It is also to remark that, the abstraction of the flue gases do not have an uniform distribution; the maximum value of the speed is reached in the central tap holes, simultaneously with low values of the speed thru the lateral tap holes (figure 9). 


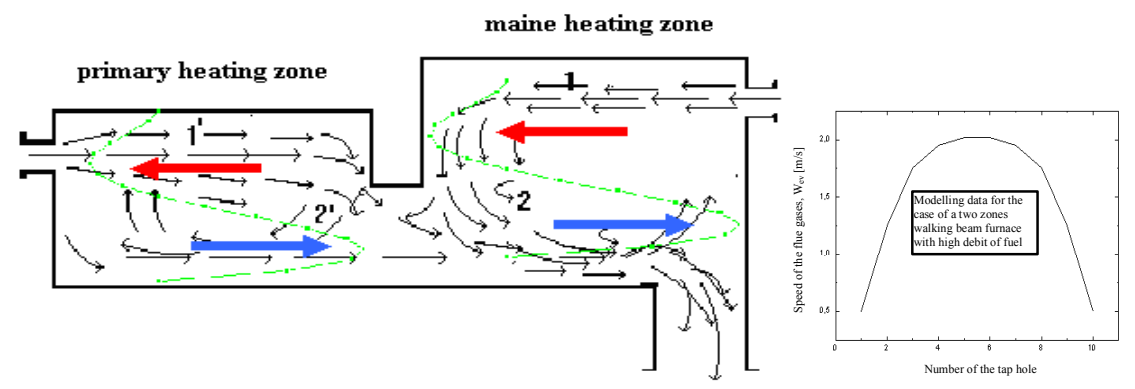

Figure 8: $\quad$ Influence of the temperature and of the jet of the gases on the dynamic in the furnace depending on the Figure 9: Speed distribution in the tap holes of the furnace. heating zone.

If the temperature has a higher value at the superior levels of the furnace, comparing to the hearth level, it will influence differently the dynamic regime in the two zones (figure 8)

Introducing and applying some hypothesis about the very closed values for the thermal capacity at the level of the primary and recycled jets, the recycling coefficient can be expressed.

The dependence of the dynamic recycling coefficient $\mathrm{K}$ on the temperatures is presented in figure 10 .

\section{Design of the thermal space of the furnace}

The dynamic design of the furnace obtained when applying the mathematical model may assure a $41 \%$ to $55 \%$ decrease of heating time, (from 153 minutes to 90minutes), corresponding to a similar decrease of energy consumption [8].

It is also possible to reduce the oxidation of the steel till $0.8 \div 1.4 \%$.

Practically, it means to propose a variable geometry of the thermal space. The basic schema corresponding to the thermal diagram is presented in figure 11 .

The model includes some particularities for the geometry of the furnace:

- there are three groups of burners:

- group $A_{1}$ using air from the heat recovery R1 which can assure a higher temperature at the superior level of the furnace

- group $\mathrm{A}_{2}$ : burners using air from R2 in order to assure a lower temperature at the inferior levels of the furnace

- group of special AFRP burners

- group $\mathrm{A}_{3}$ : are in function only in special conditions, in connection with the geometry of the thermal space in the first heating zone

- groups $\mathrm{A}_{1}$ and $\mathrm{A}_{2}$ are connected to the tap holes system in order to control the dynamic regime of the gases

- the exit of the flue gases is at the level of the vault 


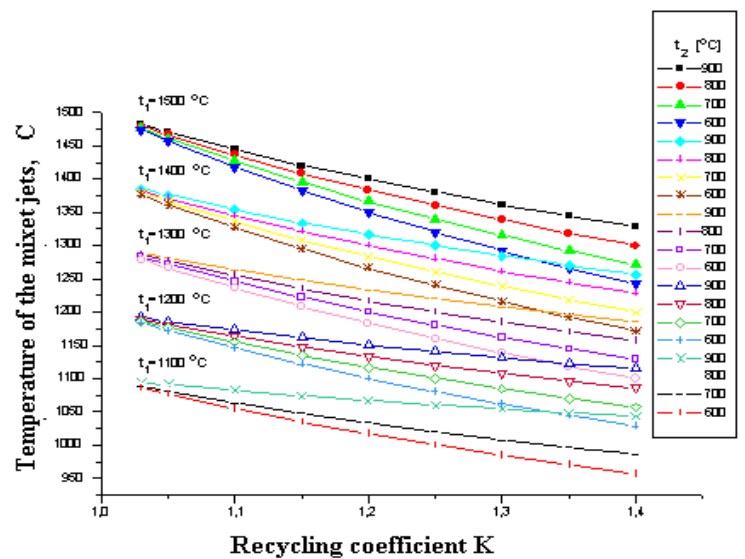

Figure 10: Establishing of the temperature of the mixed jets $t_{a}$, using the recycling coefficient.

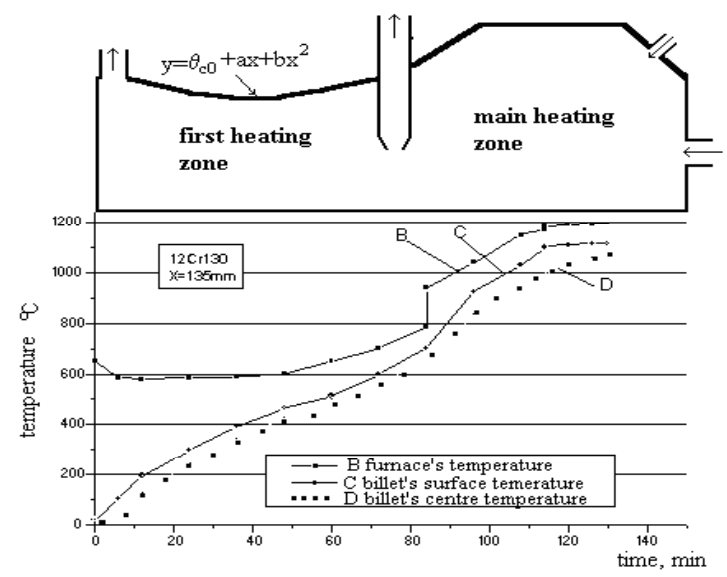

Figure 11: A basic schema for modelling the geometry of the continuous furnace (walking beam furnace).

- the evacuation system of the gases assure the condition $\theta_{b}<\theta_{v}$ in the first zone of the furnace

- in order to assure the dynamic and thermal regime, the geometry of the vault (especially in the first zone) is decisive

- the low oxidation level of the steel is also highly influenced by the profile of the vault in the first zone

\section{Discussion}

The results of the studies about the thermal stresses are the base of the remodelling of the geometry of the thermal space of the furnace. From this, the 
aspects regarding the design of the vault are essential in determining the dynamic and the thermal solutions.

If a various range of steel with different thermal properties is heated in the furnace, a variable geometry of the thermal space will bring important economies of energy and metal.

Starting from the diagrams of the variation of maximum admitted temperature of the furnace it is possible to model the vault of the continuous working furnace.

Using the proposed general solutions for the remodelling of the thermal regime it can be obtained a better control of the temperatures in each heating zone of the furnace and to correlate it with the necessary temperatures of the billets. It is also possible to control the temperature of the thermal isolation, and by this to save thermal energy.

Using the results of the modelling, it is possible to control the flue gases temperature in each heating zone of the furnace in connection with the temperature of the steel.

The basics of the general solution of the model allowed to establishing the disposal mode of the burners in connection with the design of the furnace and the necessary output. The design of the furnace can be also changed having in view the thermal and the dynamic particularities of the flow gases.

\section{References}

[1] Constantinescu, D., Nicolae, A., A model regarding the heating of steel billets in view of plastic deformation, Metalurgia, Bucuresti, vol. I, no.4. $\mathrm{p}$. 22, 1996

[2] Constantinescu, D., Nagy, D.: Tensiuni termice in semifabricatele din otel incalzite in vederea deformarii plastice, BRAMAT99", Brasov, volumul III, sectia III, pag.108, 1999

[3] Constantinescu, D: Thermal stresses in steel billets and temperature level in furnaces for rolling mills; Scientific Bulletin UPB, vol.62, nr.1/2000, pag.127 ISSN 1454-2331

[4] Heligenstaedt, W., Thermique appliqué aux fours industriels, Dunod, Paris, 1979

[5] Stanley, P., Dulieu-Smith, J.P.: The determination of crack-tip parameters from thermoplastic data, Experimental Techniques vol.20 nr.2/1996

[6] Constantinescu, D., Thermal stresses when heating semi finished products for rolling, SHMD 2002, Metalurgija 3/2002, p.257 ISSN 0543-5846, Zagreb.

[7] Constantinescu, D., Mazankova, M.: Heat exchange, energy and metal saving in the furnaces for billets reheating, $5^{\text {th }}$ International Metallurgical Conference" Continuous casting of billets and modelling of steelmaking processes" vol. I, pag.343-353, October2003, Trinec, Czech Republic

[8] Constantinescu, D: Energy saving at the continuous thermal aggregates applying the variable geometry of the thermal space obtained by mathematical modeling, BRAMAT 2007, Brasov, Romania, February 2007, ISSN 1223-9631. 